\title{
A PRACTICAL TOOL FOR EVALUATING FIRE INDUCED FAILURE PROBABILITY OF STEEL COLUMNS DESIGNED BASED ON U.S. PRESCRIPTIVE STANDARDS
}

\author{
Ramla Qureshi ${ }^{1}$, Ruben Van Coile ${ }^{2}$, Danny Hopkin ${ }^{3}$, Thomas Gernay ${ }^{4}$, Negar Elhami Khorasani ${ }^{5}$
}

\begin{abstract}
Previous research has investigated and developed systematic probabilistic models for parameters involved in determining the reliability of a structure under fire. The established models have been summarized and applied in this paper to quantify and compare the reliability of steel columns protected based upon the US prescriptive approach. A set of columns with a range of section factors are selected to study the influence of utilization ratio, restraint conditions, and fuel load density on the probability of failure under fire. The results show a relatively large variation in the value of probability of failure for columns with similar fire protection rating but different section factors and utilization ratio. The influence of fuel load density is presented in the form of fragility functions, where the probabilities of failure for expected fuel load density values are discussed. In addition, the probability of failure for columns across different stories of a building is calculated, leading to the conclusion that further harmonization of safety levels can be achieved if reliability-based quantifications are introduced in the design process.
\end{abstract}

Keywords: Steel column; reliability; US prescriptive design; probability of failure

\section{INTRODUCTION}

The US fire protection industry is trained to design passive fire protection of steel buildings based on wellestablished prescriptive approaches. Alternatively, performance-based fire design can be adopted, where the engineer designs the structural system for fire as a demand. While performance-based fire engineering indeed provides a solution for exceptional structures and those with atypical consequences of failure or with complex geometry, the US industry will continue using prescriptive design for a range of simple and regular designs. To ensure consistency in safety requirements, there is a need to better comprehend the safety level (structural reliability) of such members designed following the prescriptive guidelines. The load combination for extraordinary events (i.e., for temperature effects in case of a fire) in the "ASCE 7: Minimum Design Loads for Buildings and Other Structures" assumes a conditional failure probability of approximately 0.1 , given a structurally significant fire [1]. Yet, no study has been completed to systematically quantify the inherent safety of the prescriptive approach under realistic fire conditions, and when components or sub-assemblies become part of a structural system. To fill this gap, this paper presents the following two contributions:

\footnotetext{
${ }^{1} \mathrm{PhD}$ Candidate, Department of Civil, Structural and Enviromental Engineering, University at Buffalo e-mail: ramlakar@buffalo.edu, ORCID: https://orcid.org/0000-0002-8652-5726

${ }^{2}$ Assistant Professor, Department of Structural Engineering and Building Materials, Ghent University e-mail: Ruben.VanCoile@UGent.be, ORCID: https://orcid.org/0000-0002-9715-6786

${ }^{3}$ Visiting Professor, Department of Civil and Structural Engineering, The University of Sheffield e-mail: D.J.Hopkin@,sheffield.ac.uk, ORCID: https://orcid.org/0000-0002-2559-3581

${ }^{4}$ Assistant Professor, Department of Civil and Systems Engineering, Johns Hopkins University e-mail: tgernay@,jhu.edu, ORCID: https://orcid.org/0000-0002-3511-9226

${ }^{5}$ Assistant Professor, Department of Civil, Structural and Enviromental Engineering, University at Buffalo e-mail: negarkho@buffalo.edu, ORCID: https://orcid.org/0000-0003-3228-0097
} 
- A methodology to calculate probability of failure for steel columns and the assumed probabilistic models for the random variables: the majority of assumed probabilistic distributions, including thermal and mechanical properties of steel and insulating materials and applied gravity loads, are based on a series of previous reviews and research by the authors. In addition, the results of a recent fuel load survey from 3 office buildings in the US are included and the obtained distribution of fuel load density is provided. The procedure is implemented in a new integrated computer-based code that enables automatic calculation of the reliability of steel columns in fire.

- The sensitivity of the probability of failure of columns to a number of parameters, including section factor, utilization ratio, end restraint condition, and fuel load density: the procedure is applied to a cohort of steel columns protected according to the US standards and relevant to multi-story building designs. The probability of failure of columns across different stories of a building is also presented.

The results provide an assessment of the safety levels of the prescriptive design for steel columns. The quantification of safety levels allows a systematic evaluation of risk, which can be used to harmonize safety levels across designs with similar occupancy types.

\section{METHODOLOGY}

Quantifying the reliability of a structural member under fire involves capturing uncertainty in several variables. The assumed probability distributions for random variables affect the probability of failure, thus it is important to carefully examine and select relevant probabilistic models for input variables. In this paper, the probability of failure of a column is defined by a limit state where the load-carrying capacity of the member is less than the applied axial load (i.e., resistance domain). It should be noted that similar results were obtained for the steel columns when defining the probability of failure using the temperature domain (not shown in this paper). The considered random variables are dead and live loads (i.e., demand load), and thermal and mechanical properties of steel and insulating materials. The assumed distributions for the random variables are selected based upon rigorous evaluations of different models in the prior work of the authors (discussed in more detail in Section 2.0). In addition, column size, height, boundary conditions, hourly rating (under standard fire exposure) for the prescriptive approach (or thickness of the insulation), and fire scenario should be defined. This section provides a brief overview of the methodology and implemented random variables. Figure 1 shows the required inputs to calculate the probability of failure for a steel column.

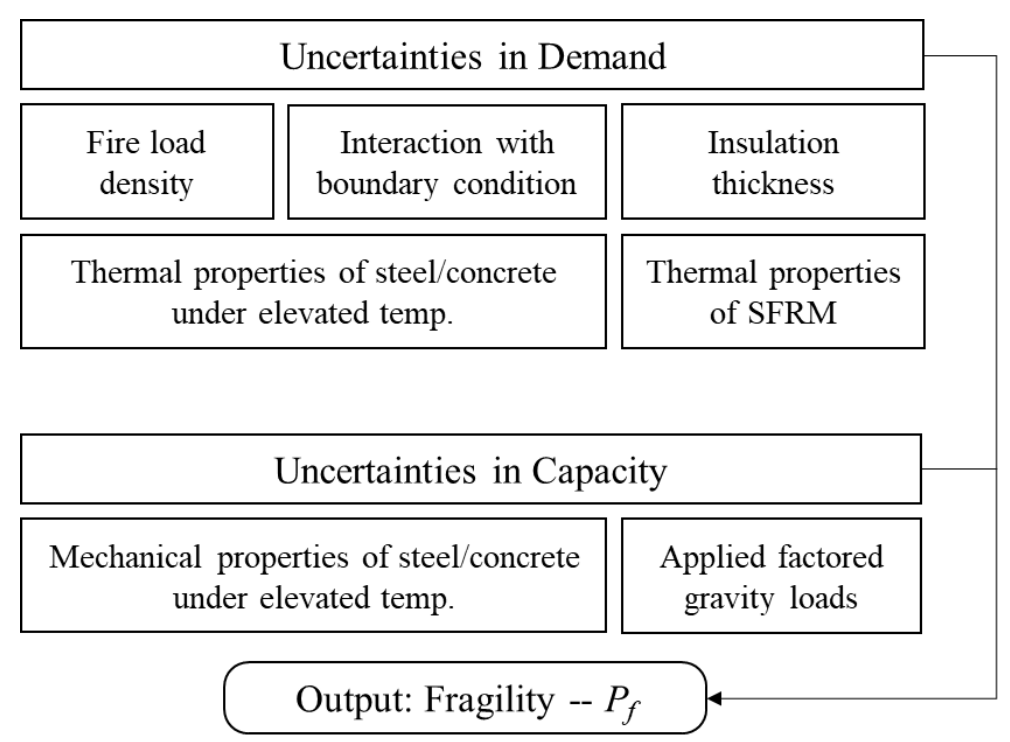

Figure 1. Overview of required inputs to calculate probability of failure for a steel column (note: parameters can be taken as deterministic or probabilistic) 


\subsection{Column capacity}

The nominal compression strength of the column is calculated and compared using two approaches, namely: (1) the provisions of Appendix 4 in AISC SCM [2], and (2) the provision of EC3 [3]. These approaches capture global buckling as a limit state, but do not capture local instabilities of the plates; therefore, the studied columns are selected to be class 3 or above (based on the Eurocode classification of cross-sections). The AISC SCM Appendix 4 sets forward equations 1 and 2 for calculating the critical compressive stress as a function of temperature, where $k_{y, \theta}$ and $k_{E, \theta}$ are reduction factors for yield strength and modulus of elasticity at elevated temperatures, $f_{y}$ is the yield stress (at ambient temperature), $E$ is the modulus of elasticity (at ambient temperature), $L_{c}$ is the effective length of the column, $r$ is the radius of gyration, and $F_{e}(\theta)$ is the critical elastic buckling stress. $L_{c}$ is determined as $k L$ where $k$ is the effective length coefficient considering the end restraints, and $L$ is the length of the column. The compression capacity is obtained by multiplying the critical compressive stress with the cross-section area of the column. The AISC commentary of Appendix 4 provides an adjustment for the column slenderness ratio considering rotational restraints offered by cooler columns in stories above and below. The adjustment reduces the column slenderness as a function of temperature and having cooler columns both above and below or only on one side. The revised slenderness ratio improves the fire resistance capacity of the column. This adjustment is not directly considered in this paper, rather the column strength is calculated for a range of $k$ values.

$F_{c r}(\theta)=\left[0.42^{\sqrt{\frac{k_{y, \theta} f_{y}}{F_{e}(\theta)}}}\right] k_{y, \theta} f_{y}$

$F_{e}(\theta)=\frac{\pi^{2} k_{E, \theta} E}{\left(\frac{L_{c}}{r}\right)^{2}}$

The EC3 provisions for calculating the capacity of a column as a function of temperature are shown in equations 3-7, where $\chi_{f i}$ is the reduction factor for flexural buckling at elevated temperatures, $A$, and $I$ are the area and moment of inertia of the column, $\gamma_{M, f i}$ is the partial factor for material property taken as 1.0 for properties of steel, and finally $\bar{\lambda}$ is the non-dimensional column slenderness at normal temperature.

$$
\begin{aligned}
& N_{b, f i, t, R d}=\chi_{f i} A k_{y, \theta} f_{y} / \gamma_{M, f i} \\
& \chi_{f i}=\frac{1}{\varphi_{\theta}+\sqrt{\varphi_{\theta}^{2}-\bar{\lambda}_{\theta}^{2}}} \\
& \varphi_{\theta}=\frac{1}{2}\left[1+\alpha \bar{\lambda}_{\theta}+\bar{\lambda}_{\theta}^{2}\right] \\
& \alpha=0.65 \sqrt{235 / f_{y}} \\
& \bar{\lambda}_{\theta}=\bar{\lambda} \sqrt{\left[\frac{k_{y, \theta}}{k_{E, \theta}}\right]} \\
& \bar{\lambda}=\sqrt{\frac{A f_{y}}{\frac{\pi^{2} E I}{L_{c}^{2}}}}
\end{aligned}
$$

Based upon the AISC commentary notes of Appendix 4, the AISC equation (post 2010 edition) provides a relatively close prediction of strength when compared with finite element models validated by test data. The AISC equation, in comparison to the EC3 method, provides slightly smaller column strength values, which would result in larger probability of failure. 


\subsection{Fire scenario}

Two fire exposure scenarios are considered in this paper: (1) the ASTM E119 fire, and (2) the parametric temperature-time curve. In the former case, the probability of failure is calculated for a given fire-resistance rating (e.g., 2 hours). In the latter case, the probability of failure is calculated as a function of fuel load density. Given the variability of fuel load density and its importance in determining the fire gas-phase temperature, the results are presented in terms of fragility curves as a function of fuel load density. A discussion on the distribution of fuel load density is provided in Section 2.3.3. The opening factor and size of the compartment are assumed as deterministic values when calculating the probability of failure for a given column. However, these variables can also be treated as random variables.

\subsection{Random variables}

Table 1 lists the random variables and associated probability distributions. The rest of this section provides a brief background for each parameter.

Table 1. Summary of random variables considered for calculating probability of failure of a steel column

\begin{tabular}{|c|c|c|}
\hline $\begin{array}{l}\text { Stochastic } \\
\text { variable }\end{array}$ & Description & Ref \\
\hline \multicolumn{3}{|c|}{ Thermal model: insulating materials } \\
\hline Density $\left[\mathrm{kg} / \mathrm{m}^{3}\right]$ & $\rho_{i}=\exp \left(-2.028+7.83 \times T^{-0.0065}+0.122 \times \varepsilon\right)$ & {$[4]$} \\
\hline $\begin{array}{l}\text { Thermal } \\
\text { conductivity } \\
{[\mathrm{W} / \mathrm{m}-\mathrm{K}]}\end{array}$ & $k_{i}=\exp \left(-2.72+1.89 \times 10^{-3} T-0.195 \times 10^{-6} T^{2}+0.209 \times \varepsilon\right)$ & [4] \\
\hline $\begin{array}{l}\text { Specific heat } \\
{[\mathrm{J} / \mathrm{kg}-\mathrm{K}]}\end{array}$ & $c_{i}=1700-\exp \left(6.81-1.61 \times 10^{-3} \times T+0.44 \times 10^{-6} T^{2}+0.213 \varepsilon\right)$ & {$[4]$} \\
\hline Thickness & Lognormal with mean $=$ nominal $+1.6 \mathrm{~mm}$ and $\mathrm{COV}=0.2$ & {$[5]$} \\
\hline \multicolumn{3}{|c|}{ Structural model } \\
\hline $\begin{array}{l}\text { Steel yield } \\
\text { strength at } \\
20^{\circ} \mathrm{C}[\mathrm{MPa}]\end{array}$ & Lognormal with mean $=f_{y}+2 \sigma$ and $\mathrm{COV}=0.07$ where $f_{y}$ is the yield strength at $20^{\circ} \mathrm{C}$ & {$[6]$} \\
\hline $\begin{array}{l}\text { Steel yield } \\
\text { strength } \\
\text { reduction factor }\end{array}$ & $\begin{array}{c}k_{y, \theta}=\frac{1.7 \times \exp \left[r_{\text {logit }}+0.412-0.81 \times 10^{-3} \times T+0.58 \times 10^{-6} \times T^{1.9}+0.43 \times \varepsilon\right]}{1+\exp \left[r_{\text {logit }}+0.412-0.81 \times 10^{-3} \times T+0.58 \times 10^{-6} \times T^{1.9}+0.43 \times \varepsilon\right]} \\
\text { with } r_{\text {logit }}=\ln \frac{\left(k_{y, E N}+10^{-6}\right) / 1.7}{1-\left(k_{y, E N}+10^{-6}\right) / 1.7}\end{array}$ & [4] \\
\hline $\begin{array}{l}\text { Steel modulus } \\
\text { of elasticity } \\
\text { reduction factor }\end{array}$ & $k_{E, \theta}=1.1 \times \frac{e^{\left(2.54-2.69 \times 10^{-3} \times T-2.83 \times 10^{-6} T^{2}+0.36 \times \varepsilon\right)}}{e^{\left(2.54-2.69 \times 10^{-3} \times T-2.83 \times 10^{-6} T^{2}+0.36 \times \varepsilon\right)}+1}$ & [4] \\
\hline $\begin{array}{l}\text { Applied load } P \\
{[\mathrm{kN}]}\end{array}$ & $\begin{array}{l}\text { Permanent load } G \text { : Normal with mean of nominal value and } \mathrm{COV}=0.10 \\
\text { Live load } Q \text { : Gumbel distribution with mean of } 0.2 \times \text { nominal value and } \mathrm{COV}=0.95 \\
\text { Model uncertainty load effect } K_{E} \text { : Lognormal with mean } 1.0 \text { and } \mathrm{COV}=0.10\end{array}$ & [7] \\
\hline $\begin{array}{l}\text { Model } \\
\text { uncertainty for } \\
\text { capacity }\end{array}$ & $K_{R}:$ Lognormal distribution, mean of 1.0 and $\mathrm{COV}=0.15$ & [8] \\
\hline
\end{tabular}

\subsubsection{Thermal model}

The thermal properties of the insulating material, including density, thermal conductivity, and specific heat are modelled as temperature-dependent random variables. The models were derived in [4] considering data from three sprayed fire-resistive materials (Blaze-Shield DC/F, Blaze-Shield II, and Monokote MK-5). Density has a slightly decreasing trend with temperature while thermal conductivity and specific heat have 
increasing trends with temperature. The increase in thermal conductivity with temperature is noticeable and should be considered as it leads to a larger rate of heat transfer to the section. The insulation thickness is also assumed as a random variable as defined in Table 1 . The density and specific heat of steel are modelled as deterministic values, where density is taken as $7850 \mathrm{~kg} / \mathrm{m}^{3}$ and specific heat is taken as the deterministic EC3 (temperature-dependent) model [3].

\subsubsection{Mechanical model}

The uncertainty in yield strength both at the ambient temperature and at elevated temperatures is modelled. The uncertainty at $20^{\circ} \mathrm{C}$ follows the recommendation of [6]. The reduction factors for yield strength and modulus of elasticity of steel at elevated temperatures are taken from [4]. The authors completed a comprehensive study on the effect of model choice on the probability of failure of steel columns when the yield strength reduction factor is modelled using different approaches and based on different distributions [9]. The results showed that the model choice did not seem to have a considerable effect on the probability of failure, especially in the range of $1 \%$ to $10 \%$ failure quantiles. The applied model in this paper is a logistic model with strength defined at $2 \%$ strain. At temperatures below $500{ }^{\circ} \mathrm{C}$, the median values of this model have values larger than that of EC3, reflecting the effect of strain hardening. The resistance model uncertainty in calculating the capacity of the steel columns $K_{R}$ is assumed as lognormal distribution with a mean of unity and coefficient of variation (COV) 0.15 .

Jovanovic et al. [7] reviewed relevant literature on dead load, live load, and total load for application in probabilistic structural fire engineering. The study recommended modelling the total load as listed in Table 1 with $K_{E}$ as the action model uncertainty, $G$ as the dead load, and $Q$ as the live load. The model uncertainty follows a lognormal distribution with a mean of 1.0 and COV of 0.10 . The dead load is modelled as a normal distribution with the mean taken as the nominal value and a COV of 0.10. Live load follows a Gamma distribution with the mean equal to 0.2 times the nominal value and COV of 0.95 . In determining the total load when studying the probability of failure for a series of columns, the load ratio $\chi$ is defined as the ratio of nominal live load to the total nominal load $[Q /(G+Q)]$.

\subsubsection{Fuel load density}

EC1 [10] prescribes a Gumbel distribution for fuel load density with associated mean and 80\% fractile values for different occupancy types. Figure 2 shows the distribution for office and library buildings according to the EC. Fuel load density is one of the major parameters influencing the gas-phase temperature-time distribution of fire in a compartment. Surveys of fuel load density are rare since existing surveying approaches are cumbersome. In a recent study supported by the National Fire Protection Association (NFPA), a new digitized surveying methodology was developed to collect fuel load density data by processing images of room contents using online databases [11]. Item weight and specifications are extracted through image matching within existing online search engines. The newly developed methodology was applied to 3 office buildings on a university campus in the US [12]. The obtained distribution from the collected data (34 closed offices and 161 cubicles within 12 large open plan offices) is shown in Figure 2.

The surveyed rooms had large quantities of paper, where the movable fuel load density composition was $54 \%$ paper, $30 \%$ wood, and $16 \%$ plastic, noting that no derating factor was applied for enclosed spaces. Breakdown of data in terms of furniture contribution to fuel load density consists of $36 \%$ furniture, $8 \%$ electronics, $54 \%$ paper, and $2 \%$ other. The resulting fuel load density distribution for moveable content lands in between EC1 office and library occupancy types, with a mean of $1115 \mathrm{MJ} / \mathrm{m}^{2}$ and a standard deviation of $614 \mathrm{MJ} / \mathrm{m}^{2}$. The results are based on a limited number of surveyed offices located on a university campus. However, the difference between obtained values and the distribution from EC1 is significant. Thus, the results emphasize the need to conduct more surveys of modern buildings and potentially investigate occupancy sub-classifications to, for example, distinguish between different office types to account for the expected type of load (e.g., large loads of papers in offices on a university campus). 


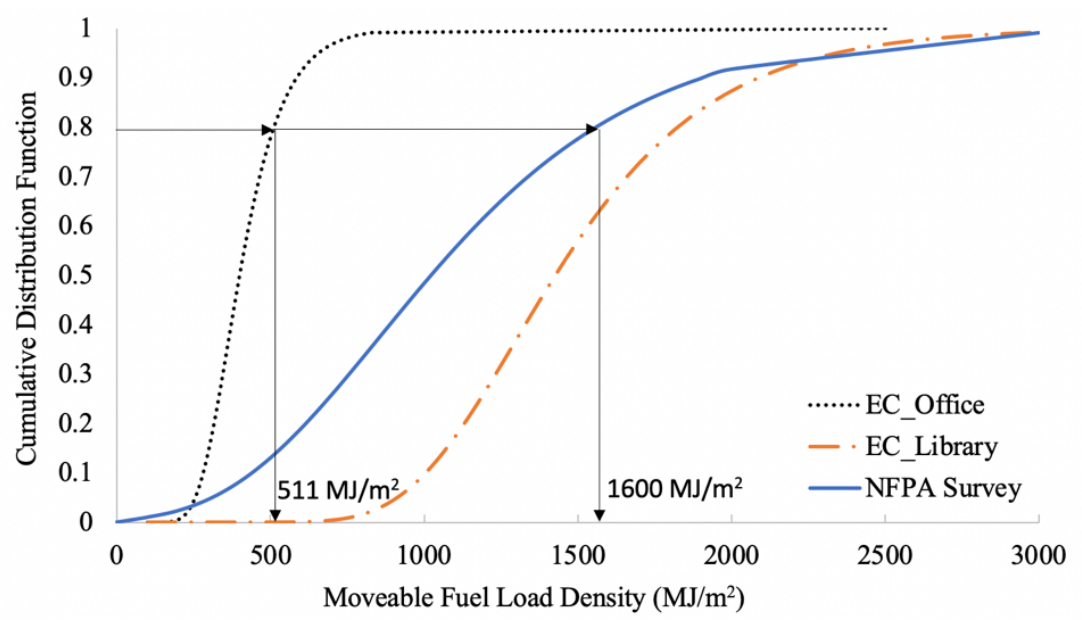

Figure 2. Fuel load density distributions from EC1 and recent survey of 3 office buildings in the US

\section{APPLICATION}

The probability of failure of a cohort of columns, with a range of section factors, is first calculated and compared for different utilization ratios and end restraint conditions when subjected to 2 hours of the ASTM

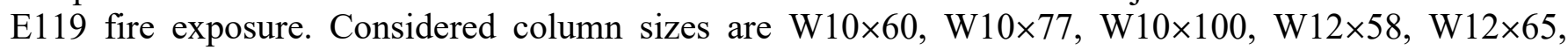
$\mathrm{W} 12 \times 79, \mathrm{~W} 12 \times 106, \mathrm{~W} 12 \times 136, \mathrm{~W} 12 \times 152, \mathrm{~W} 14 \times 53, \mathrm{~W} 14 \times 68, \mathrm{~W} 14 \times 82, \mathrm{~W} 14 \times 109, \mathrm{~W} 14 \times 145$, and $\mathrm{W} 14 \times 159$. The covered range of section factors, reflecting the rate of temperature increase in the section as a function of mass and surface area exposed to fire, is 60.9 to $127.3 \mathrm{~kg} / \mathrm{m}^{2}$. The height of all columns is taken as $3692 \mathrm{~mm}$. The characteristic values for steel yield strength and modulus of elasticity at ambient temperature are taken as $345 \mathrm{MPa}$ and $200,000 \mathrm{MPa}$, respectively. The applied load is determined based on a load ratio $\chi$ (defined in Section 2.3.2) of 0.25 and the assumed utilization ratio for the case under study. The utilization ratio is defined as the ratio of demand to capacity where demand is defined as the factored design load at ambient temperature (based on load combinations in the US ASCE 7-16 code [13]) and the column capacity is calculated at ambient temperature using the AISC standard [2]. Both demand load and axial capacity are calculated using nominal values of variables.

In the second step, the probability of failure for the same set of columns is calculated as a function of fuel load density, assuming the EC parametric temperature-time curve. The compartment size is taken as 9.144 $\mathrm{m} \times 6.096 \mathrm{~m} \times 2.8 \mathrm{~m}$ (based on dimensions of a 9-story building explained next). The opening size is taken as $3.0 \mathrm{~m} \times 1.5 \mathrm{~m}$. In the last step, the probability of failure for columns from the gravity frame of a 9-story building, designed according to the US standards, are examined. The 9-story building requires a 2-hour fire rating for columns in the gravity frame. The column on the $1^{\text {st }}$ story has a $k$ value of 0.7 while the other floors have a $k$ value of 0.5 , given the end restraint conditions. Table 2 provides the list of columns for the 9 -story frame (except for the $9^{\text {th }}$ story where the column section is a class 4 at elevated temperatures and thus excluded from the analysis), the corresponding nominal dead and live loads used in the design process, and the utilization ratio at ambient temperature (UR). Details of the design and fire compartment dimensions can be found in [14].

Table 2. Column section sizes, applied load, and utilization ratio at ambient temperature

\begin{tabular}{|c|c|c|c|c|c|c|c|c|c|}
\hline Story & Size & DL [KN] & $\mathbf{L L}[\mathrm{KN}]$ & UR & Story & Size & DL $[\mathrm{KN}]$ & LL [KN] & UR \\
\hline 1 & W14×109 & 3692 & 689 & 0.96 & 5 & $\mathrm{~W} 14 \times 68$ & 2064 & 368 & 0.83 \\
\hline 2 & W14×109 & 3285 & 608 & 0.79 & 6 & W14×68 & 1657 & 288 & 0.66 \\
\hline 3 & $\mathrm{~W} 14 \times 82$ & 2878 & 528 & 0.96 & 7 & $\mathrm{~W} 14 \times 53$ & 1253 & 219 & 0.67 \\
\hline 4 & $\mathrm{~W} 14 \times 82$ & 2471 & 448 & 0.82 & 8 & $\mathrm{~W} 14 \times 53$ & 849 & 148 & 0.45 \\
\hline
\end{tabular}




\section{RESULTS FOR PROBABILITY OF FAILURE OF COLUMNS}

\subsection{Sensitivity of probability of failure to various parameters}

This section studies variation in the probability of failure for a cohort of columns listed in Section 3 . The columns are assumed to be protected with Isolatek Blaze-Shield II insulation with the specified nominal thickness corresponding to the 2-hour rating (the 2-hour rating is selected to have comparable results with those of the 9-story building described in Section 3). The fire protection material specification and design aid tables for insulation thickness provided by the manufacturer can be found in [15]. The probability of failure is obtained by generating 5,000 parameter combinations using Latin Hypercube Sampling (LHS) with $f_{y}, k_{y, \theta}, E, k_{E, \theta}, \rho_{i}, k_{i}, c_{i}$, thickness of insulation, applied load, and model error taken as random variables. Figure 3 shows the variation in the probability of failure assuming 2 hours of the ASTM E119 fire, a load ratio $\chi$ of 0.25 , and a $k$ value of 1.0. For the same fire rating, columns with a larger W/D ratio have a smaller probability of failure. The performance criteria in determining the insulation thickness during standard furnace tests of columns in the prescriptive approach mainly relate to temperature limits in the cross section during the test (e.g., average temperature should remain below $538^{\circ} \mathrm{C}$ or temperature at no one location along the member should exceed $649^{\circ} \mathrm{C}$ ). Depending on the available resources and capabilities of the laboratory conducting the standard test, the column may not be loaded. The variation in probabilities of failure presented in Figure 3 reflects the change in slenderness ratio of the columns as the section sizes change.

In addition, columns with a higher utilization ratio have a larger probability of failure, as the prescriptive approach does not take the utilization ratio into account. The selected utilization ratios are consistent with those listed in Table 2 for the 9-story building. As expected, when capacity is calculated using the AISC SCM provisions, a larger probability of failure is obtained compared to the EC3 calculation, given that the AISC SCM provides slightly lower capacity predictions. The calculated range of probability of failure is relatively large, varying between 0.1 and 0.6 for W/D values between 60 and 140 and the utilization ratio of 0.55 .

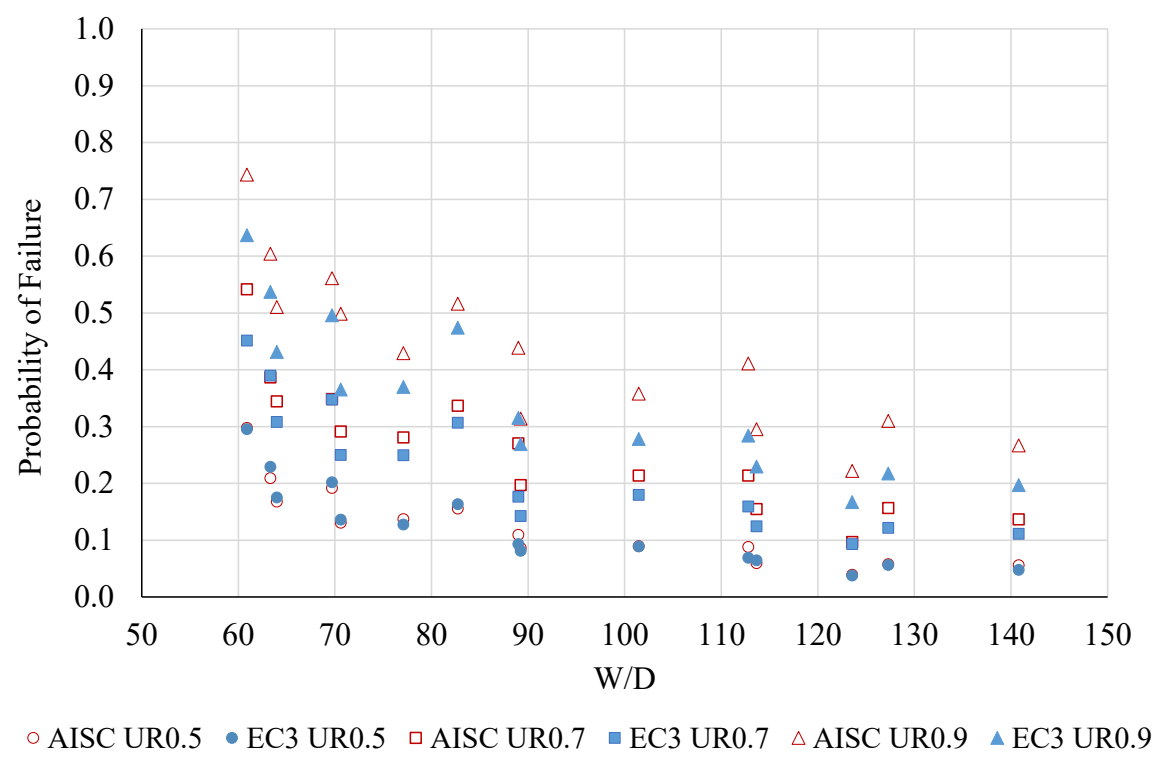

Figure 3. Probability of failure versus W/D ratio for different utilization ratios, assuming load ratio $=0.25, \mathrm{k}=1.0$, and $\mathrm{H}=$ $3962 \mathrm{~mm}$

Figure 4 shows the change in the probability of failure as a function of end restraint condition, calculated using AISC. The influence of end condition is more pronounced for columns with a lower W/D ratio. For example, a column with a W/D ratio of 60 has a probability of failure ranging from about 0.34 to about 0.55 by changing the end conditions from fixed to pinned at both ends. Such difference is not observed for columns with W/D ratio above 100 where the probability of failure is equal to or less than 0.2 . For a given length, load ratio, and utilization ratio, the columns with smaller W/D ratio have larger slenderness ratio 
(given a smaller radius of gyration). The larger variation in the probability of failure at lower W/D values can be explained by the higher sensitivity of cases that are more slender.

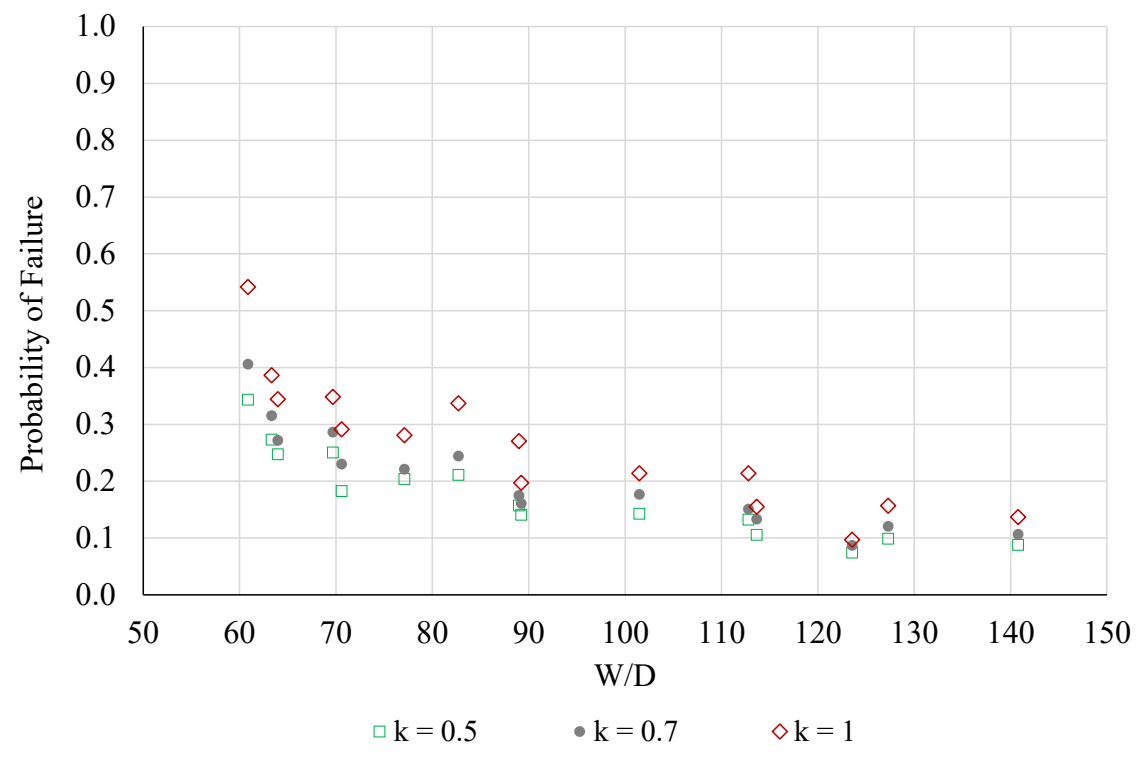

Figure 4. Probability of failure versus W/D ratio for different $\mathrm{k}$ values, assuming load ratio $=0.25$, utilization ratio $=0.7$, and $\mathrm{H}=3962 \mathrm{~mm}$

Figure 5 shows the probability of failure as a function of the (deterministic) fuel load density. In this case, the fire scenario is changed to the parametric temperature-time curve and the probability of failure is calculated considering the full duration of fire until burnout. Here, 10,000 LHS combinations (to ensure convergence in probability of failure at high values of fuel load density) were used to generate the probability of failure. The nominal insulation thickness is kept the same as that specified for the 2-hour rating.

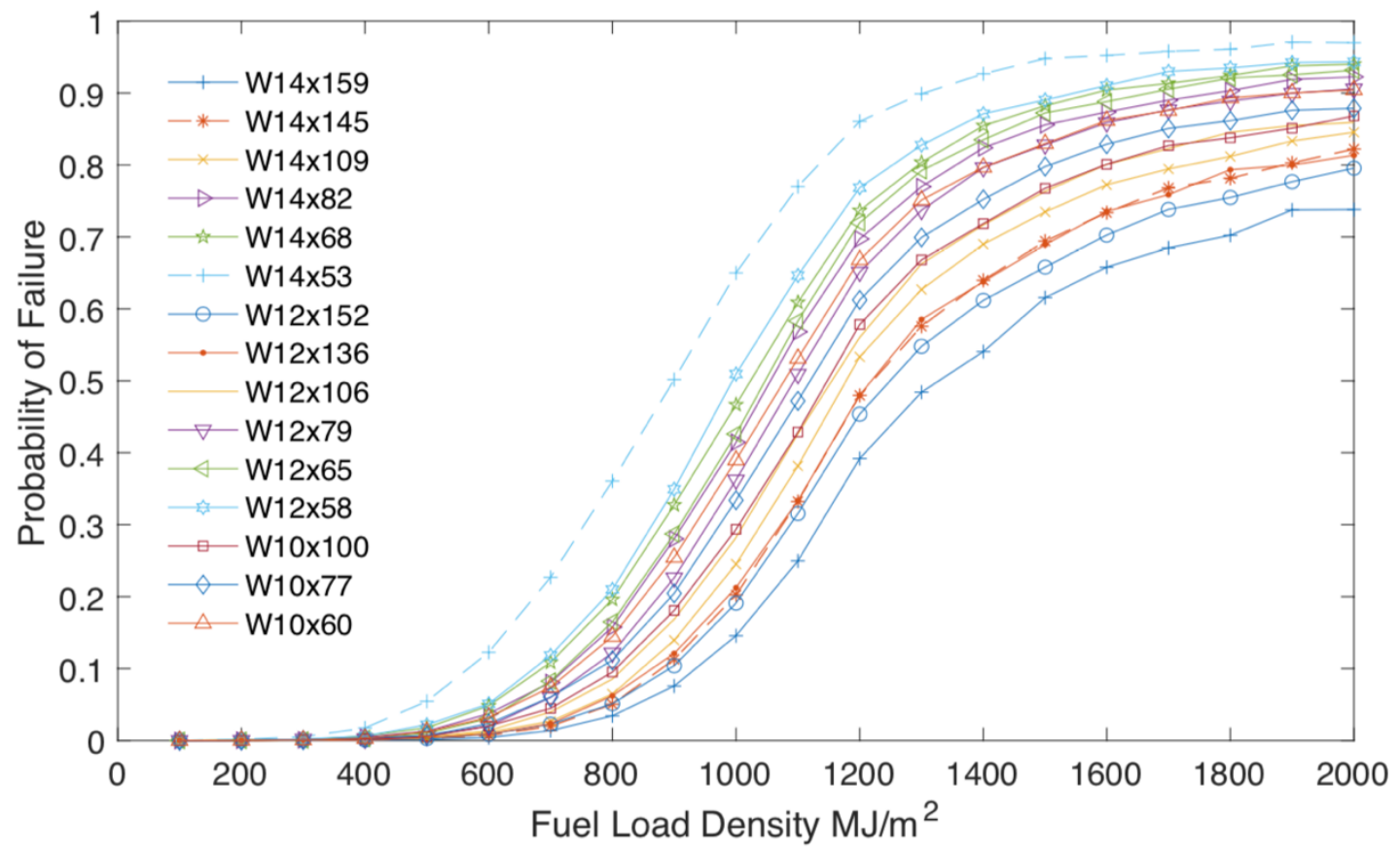

Figure 5. Probability of failure as a function of fuel load density, assuming load ratio $=0.25$, utilization ratio $=0.7, \mathrm{k}=1.0$, and $\mathrm{H}=3962 \mathrm{~mm}$ 
The fragility function representation of results provides an opportunity for the structural engineer to obtain the reliability of a design considering the distribution of fuel load density for the building under study. Based on the discussion in Section 2.3.3, the EC1 80\% quantile fuel load density value for offices is 511 $\mathrm{MJ} / \mathrm{m}^{2}$, which implies a probability of failure ranging from 0.002 to 0.065 , for this characteristic fire load density. The lower and upper bounds of the probability of failure change to 0.66 to 0.95 respectively, when considering the $80 \%$ quantile of fuel load density $\left(1600 \mathrm{MJ} / \mathrm{m}^{2}\right)$ from the 3 newly surveyed office buildings in the US. These results show that the fuel load density in a compartment significantly influences the fire severity, and hence the probability of failure. While a 2-hour prescriptive rating allowed most columns to survive until full burnout when adopting the EC1 office occupancy distribution with the assumed compartment characteristics, failure was much more likely when adopting the fuel load distribution from the recent survey. When considering the uncertainty in the fuel load density, the fragility curve of Figure 5 allows to obtain a single value failure probability for the column in function of the occupancy type.

\subsection{Variation in the probability of failure within a building}

The procedure of Section 4.1 is applied to columns of the 9-story building described in Section 3 to investigate the reliability level in a given structure. The structure requires a 2-hour fire rating, the associated insulation thickness is applied to the columns, and the probability of failure is calculated for 2 hours of ASTM E1 19 fire exposure. Figure 6 shows the results as a function of building story and based on both AISC SCM and EC3 capacity calculations. The figure shows that the column on the $8^{\text {th }}$ story has the smallest probability of failure due to a smaller utilization ratio. The results also show the variation in the probability of failure with values in the range of 0.5 to 0.2 on the $1^{\text {st }}$ and $8^{\text {th }}$ stories where the design conditions (e.g., height, end restraint, load) are different.

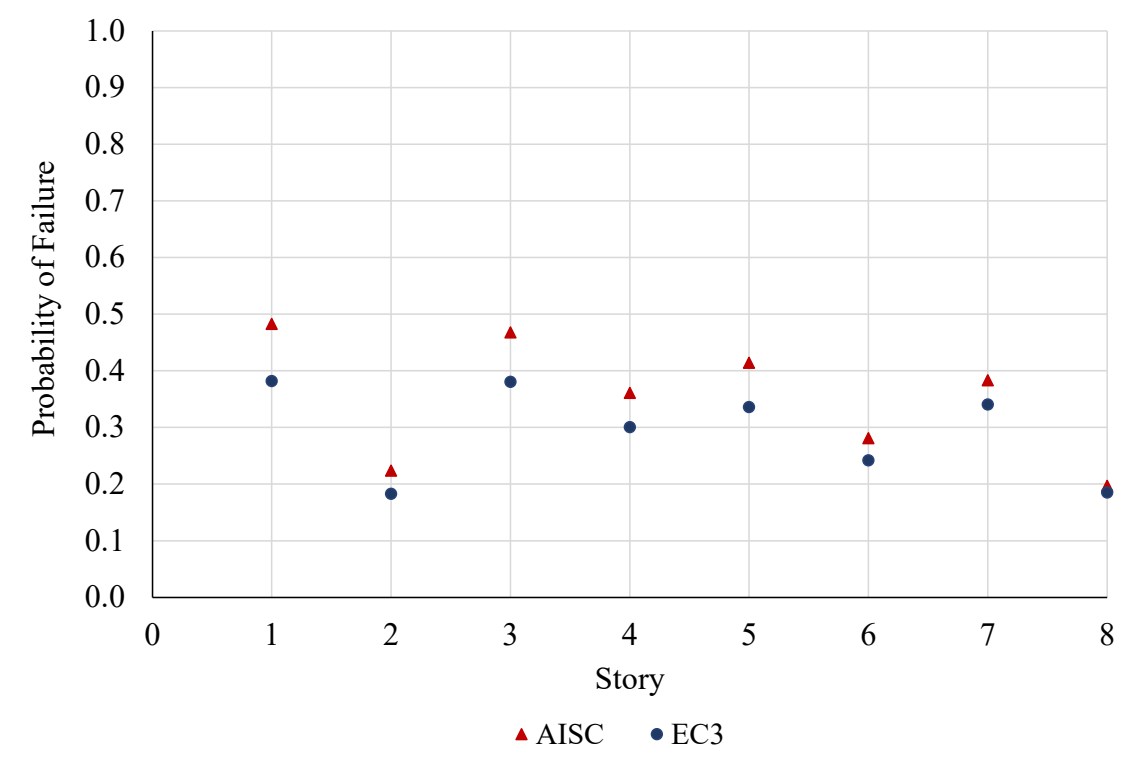

Figure 6. Probability of failure for columns in the gravity frame of a 9-story building

\subsection{Discussion}

The results presented in Sections 4.1 and 4.2 showed that the section factor and utilization ratio have a considerable influence on the probability of failure of steel columns protected based upon US prescriptive design approach. Another parameter that was not discussed earlier but could affect the probability of failure is the thermal conductivity of the fire protection. The properties of the insulating material, including thermal conductivity, specific heat, and density, are proprietary and typically listed by manufacturers at ambient temperature only. However, limited experimental data show that these properties change with temperature, more specifically, the thermal conductivity of insulating material changes from 0.065 to $0.378 \mathrm{~W} / \mathrm{mK}$ on average at 25 and $1000{ }^{\circ} \mathrm{C}$, respectively [16]. Thus, using the listed values at ambient temperature for properties of insulating material does not provide realistic results and leads to values of probability of failure 
that are an order of magnitude smaller. The results presented in this paper include randomness as well as the temperature-dependent variation of thermal properties.

In terms of an acceptable threshold for the probability of failure of steel columns, Ellingwood assumed a conditional failure probability of approximately 0.1 for structural elements given a structurally significant fire to arrive at the design load combination when including fire. It is not the intent of this paper to discuss acceptable reliability thresholds and it should be mentioned that structural collapses due to fire in the US are considered to be rare. However, there are two discussion points to be considered when evaluating the reliability of structures under fire: (1) the probability of failure of elements should be quantified and guidance should be provided to ensure a harmonized safety level for structures of similar occupancy type, an approach that is not currently being followed, (2) the fire protection design of structural elements, designed based upon prescriptive or performance-based approaches, can be optimized if the design follows a target safety level.

\section{CONCLUSIONS}

This paper completed a systematic comparison of the probability of failure for a set of steel columns designed based upon the US prescriptive approach with varying section factor $\left(60.9\right.$ to $\left.127.3 \mathrm{~kg} / \mathrm{m}^{2}\right)$, utilization ratio $(0.5,0.7$, and 0.9$)$, and end restraint condition $(k$ of $0.5,0.7$, and 1.0$)$. The limit state was defined in the load domain, comparing axial demand load and capacity, where capacity was calculated using either AISC SCM or EC3 approaches. The columns were subjected to the ASTM E119 and parametric temperature-time curve considering a range of fuel load density (up to $2000 \mathrm{MJ} / \mathrm{m}^{2}$ ). The probability of failure was calculated with the yield strength of steel, modulus of elasticity of steel, density, thermal conductivity, specific heat, and thickness of insulation, applied load, and model error as random variables. The applied probabilistic models for the random variables were carefully selected based on the prior studies by the authors. The process was implemented in a code for future applications by engineers and researchers.

The presented results in this paper showed a relatively large variation in the probability of failure when considering columns with different section factors. The US prescriptive approach also does not consider the effect of utilization ratio in the prescribed insulation thicknesses. Limiting the comparison to columns of a 9-story building designed according to current prescriptive codes, the probability of failure still varied between 0.2 and 0.5 , where the largest difference occurred for first and last stories with different height, applied load, and end restraint conditions. One question that needs to be further investigated relates to the thermal properties of insulating materials that are proprietary. Values of the probability of failure are sensitive to the input properties, including thermal conductivity of insulation. In general, the level of safety of the US prescriptive approach practiced for decades can be acceptable, yet, the reliability level is not known and has not been established. Results presented in this paper demonstrate that a more harmonized safety level for more efficient and economic designs should be investigated, which will also ensure known, consistent, and quantified safety levels for structural fire design.

\section{REFERENCES}

1. Ellingwood, B., Load combination requirements for fire-resistant structural design. Journal of Fire Protection Engineering, 15, 2005, pp. 43-61.

2. American Institute of Steel Construction (AISC), Specification for structural steel buildings, ANSI/AISC 360-16, Chicago, IL, 2017.

3. CEN: European Committee for Standardization, General rules - structural fire design - EN1993-1-2, Eurocode 3, Brussels: Belgium, 2005.

4. Elhami Khorasani, N., Gardoni, P., Garlock, M., Probabilistic fire analysis: material models and evaluation of steel structural members. Journal of Structural Engineering 141, 2015, 12, 04015050.

5. Iqbal, S, Harichandran, R.S., Capacity reduction and fire load factors for design of steel members exposed to fire. Journal of Structural Engineering, ASCE, 136(12), 2010. 
6. Holický, M., Sýkora, M., Stochastic models in analysis of structural reliability. Proceedings of the international symposium on stochastic models in reliability engineering, life sciences and operation management, Beer Sheva, 08-11/02, Israel, 2010.

7. Jovanovic, B., Van Coile, R., Hopkin, D., Elhami Khorasani, N., Lange, D., Gernay, T., Review of current practice in probabilistic structural fire engineering - permanent and live load modelling, Fire Technology, 2020, https://doi.org/10.1007/s10694-020-01005-w.

8. Van Coile, R., Hopkin, D., Elhami Khorasani, N., Gernay, T., Demonstrating adequate safety for a concrete column exposed to fire using probabilistic methods, Fire and Materials, 2020, https://doi.org/10.1002/fam.2835.

9. Qureshi, R., Ni, S., Elhami Khorasani, N., Van Coile, R., Hopkin, D., Gernay, T., Probabilistic models for temperature dependent strength of steel and concrete, ASCE Journal of Structural Engineering, 146(6), 2020. https://doi.org/10.1061/(ASCE)ST.1943-541X.0002621

10. CEN: European Committee for Standardization, Actions on structures-Part 1-2: General actions-Actions on structures exposed to fire. Eurocode1, Brussels, Belgium, 2002.

11. Elhami Khorasani, N., Salado Castillo, J.G., Gernay, T., A digitized fuel load surveying methodology using machine vision, Fire Technology, 2020, https://doi.org/10.1007/s10694-020-00989-9

12. Elhami Khorasani, N., Salado Castillo, J.G., Saula, E., Josephs, T., Nurlybekova, G., Gernay, T., Application of a digitized fuel load surveying methodology to office buildings, Fire Technology, 2020, https://doi.org/10.1007/s10694-020-00990-2.

13. ASCE, Minimum Design Loads for Buildings and Other Structures (ASCE/SEI 7-16), American Society of Civil Engineers, Reston, VA, 2016.

14. Gernay, T., Elhami Khorasani, N., Garlock, M.E.M., Fire fragility functions for steel frame buildings: Sensitivity analysis and reliability framework, Fire Technology, 55, 1175-1210, 2019.

15. Isolatek, Isolatek international product manual, Isolatek International, Stanhope, NJ, 2020.

16. Carino, N.J., Starnes, M.A., Gross, J.L., Yang, J.C., Kukuck, S.R., Prasad, K.R., Bukowski, R.W., Passive fire protection, Federal building and fire safety investigation of the World Trade Center disaster, NIST NCSTAR 1-6A, 2005. 